\title{
DAILY MOTIVATION THROUGH SOCIAL MEDIA DURING PANDEMIC HAS A GOOD IMPACT ON STUDENTS' LIFESTYLES, HBA1C, AND LIPID PROFILES
}

\author{
Irfannuddin Irfannuddin ${ }^{1, *}$, Eka Febri Zulissetiana ${ }^{1}$, Tyas Hestiningsih $^{2}$, Indra Franajaya ${ }^{3}$, Subandrate ${ }^{4}$, \\ and Susilawati ${ }^{5}$
}

\author{
${ }^{1}$ Department of Physiology, Faculty of Medicine, Universitas Sriwijaya, Indonesia \\ ${ }^{2}$ Department of Dentistry, Faculty of Medicine, Universitas Sriwijaya, Indonesia \\ ${ }^{3}$ Siti Fatimah General Hospital, South Sumatra, Indonesia \\ ${ }^{4}$ Department of Biochemistry, Faculty of Medicine, Universitas Sriwijaya, Indonesia \\ ${ }^{5}$ Department of Medical Education, Faculty of Medicine, Universitas Sriwijaya, Indonesia
}

${ }^{*}$ Corresponding authors: Irfannuddin Irfannuddin

Email: irfan.md@unsri.ac.id

\begin{abstract}
A school activity has been limited due to the COVID-19 pandemic. Learning from home can lead to a sedentary lifestyle. An innovative program is needed to maintain a healthy lifestyle among students at home. A study to give daily motivation via social media has been conducted to improve students' lifestyles. At once, the study measured its impact on indicators of metabolic syndrome. The overweight and obese students $(n=160)$ were divided into intervention and control groups. Both of them received brief education and motivation to live a healthy lifestyle. Furthermore, the intervention group was given daily supportive motivation messages through the social media group, which was not given to the control group. Lifestyle indicators were measured by step count application, physical activity questionnaire, and the semi-quantitative-food frequency questionnaire. Body Mass Index, HbA1c, and lipid profile measurements were also conducted. An ANCOVA test showed that the intervention group had more daily steps and physical activity than the control $(p<0.05)$. Calorie intake was also lower in intervention group $(p<0.05)$. The intervention group also had better $B M I, H b A 1 c$, and all lipid profiles $(p<0.05)$. Daily motivation should be given to students to improve their lifestyles so that it results in positive effects on metabolic syndrome indicators.
\end{abstract}

Keywords: Pandemic, Lifestyles, Motivation, Social media

\section{INTRODUCTION}

The COVID-19 has first appeared in Wuhan, China in early December 2019 and spread to the world including Indonesia. ${ }^{1}$ The first COVID-19 case in Indonesia was detected on March 2, 2020, and continues to spread. Various countries have tried to prevent the spread of the virus by implementing a lock-down system. ${ }^{2}$ The Indonesian government was implementing a similar method, with the term "large-scale restrictions". All crowd activities including office and school activities were restricted. Almost all work and school activities must be carried out from home. Until the end of 2020, most schools in Indonesia were still implementing learning from home due to the high transmission rate. ${ }^{3}$

Work or study from home has the risk of changing lifestyles to be more sedentary. ${ }^{4}$ Changes in sedentary lifestyles are not only seen in adults but are also seen in children and adolescents. ${ }^{5}$ Learning activities at home in children and adolescents reduce their level of daily physical activity. Children fill their time with playing gadgets and watching television or computer. Watching television has been studied to be associated with an increase in waist diameter in both men and women. ${ }^{6}$ Continuous sedentary behavior increases the risk of developing metabolic syndrome. ${ }^{8}$ Metabolic syndrome is a combination of cardio-metabolic diseases that increase the risk of early death. ${ }^{9}$ The incidence of metabolic syndrome is not only seen in adults but is also found in children and adolescents with similar symptoms. ${ }^{9,10}$

Metabolic syndrome can be prevented by a healthy diet and increasing physical activity. ${ }^{11}$ Schools in Indonesia have a curriculum that contains physical activity programs for their students. Physical education is one of the mandatory subjects in schools to help children to be healthy. ${ }^{12}$ During the pandemic, all students are required to conduct online learning, so that the physical activity program would not be implemented. An innovative program is needed to maintain a healthy lifestyle in children and adolescents at home. However, studies reveal an effective method of maintaining the physical activity of children at home during a pandemic is still limited. We conducted a trial using social media to motivate adolescents to improve their physical activity. A study was also conducted to assess the impact of this motivation on indicators of metabolic syndrome. 


\section{METHODS}

Data retrieval was performed twice, once before the intervention and did again 3 months later. Data collection was carried out in conjunction with the rapid immune-serological test for COVID19. This service was provided by Palembang City Health Office. The local government has the policy to carry out rapid tests for COVID-19 inspections to schools every 3 months. All examinations were carried out following WHO standard prevention for COVID-19. Students arrive gradually on schedule to prevent crowds. Besides, students were provided and asked to wear medical masks and always keep their distance during activities. Examining officers used personal protective equipment according to WHO recommendations. ${ }^{13}$

The research was carried out after obtaining approval from the Ethics Committee, Faculty of Medicine, Sriwijaya University (IDN 132-2020). Furthermore, this study has been reviewed and approved by school officials (No.164/F.2/2020) and the Palembang City Health Office (No.475/UN9/Dinkes/2020). The entire data collection was carried out under the supervision of those parties.

\section{Subjects}

The program for monitoring physical activity through social media was carried out on a group of adolescents purposely. They were students from one public high school in Palembang City, Indonesia. Based on the school's considerations, this study was only intended for students who have a BMI $\geq$ of 23 . That BMI is characterized as the overweight or obese group for Asians. ${ }^{14} \mathrm{An}$ existing data in the school's clinic recorded 203 from 1152 students (17.62\%) were eligible to be as subjects. All they received information and invitations to take part in the study. The letters were delivered along with a letter from the school. They were provided with information on requests to take part in the study. They were asked to complete questionnaires and follow a monitoring program. They were also asked to have a portion of their blood sample for a rapid test, used for lipid profile and $\mathrm{HbA1C}$ tests. One hundred and sixty (160) volunteers, age 15-17 years old, were willing to take part in the study and were able to go through the process. The informed consent was signed by their parents or guardians. Students were divided into the intervention $(n=80)$ and the control group $(n=80)$ randomly, regardless of gender. Student lists were sorted consequently based on arrival time. Students enrolled in odd numbers were included in the intervention group. Meanwhile, students with even ordinal numbers entered the control group. To minimalize drop outs, teachers were involved in monitoring. Teachers also reminded students to take part in post-intervention examinations.

\section{Intervention group}

In the early stages of the program, the intervention group was provided with health education by competent motivators. The topics were metabolic syndrome, risk factors, physical activity programs, and dietary management. After that, the subjects were invited to join the social media group. Every day, the intervention group was given motivational sentences through the social media group. The motivation sentences were about the support for doing daily physical activity and a healthy diet. All sentences were supportive and persuasive, cited from various sources. ${ }^{15-22}$ Different sentences were given every day for 3 months. The motivation sentences are shown in table 1. Besides, subjects were also asked to download the pedometer application and join a group.

\section{Control group}

The control group was provided with education on the same topic and by the same motivators. Subjects then were invited to join the social media group without monitoring their daily life patterns. Yet, this group was not given motivational sentence intervention. Subjects were asked to download the Pacer® pedometer application, and then they were invited to join another group.

\section{Daily Steps Calculation}

Pacer ${ }^{\circledR}$ pedometer application was used to calculate the number of daily steps. This application can be downloaded from smartphones with iOS and Android platforms. This application also can measure calories, time and distance traveled of daily activities. The selection of this application was based on the number of application users, free, and their high rating. This application has more comprehensive wellness components. One of them is the communication option between individuals. ${ }^{23}$ The application is capable of recording steps for 24 hours, it can even record the number of the steps for each hour. To keep the steps recorded, subjects were reminded to bring their device in every activity. Footsteps were recorded twice. The first record was the daily average step for the first 7 days after education. The second record was the daily average step over the 3 months intervention period. 
Table 1. Motivational sentences given to the intervention group

\author{
Those who feel they do not have time to exercise, \\ sooner or later should take the time to take care of the \\ disease. ${ }^{15}$ \\ Good health is not something we can buy. However, \\ something that can be saved with a healthy lifestyle. ${ }^{15}$ \\ Kenneth Cooper: We do not stop exercise due to we are \\ old. We are getting old due to we stopped Exercising. ${ }^{16}$ \\ After you replace negative thoughts with positive ones, \\ you will start to get positive results. ${ }^{17}$ \\ Age is indeed God's hands, but health is in our hands. ${ }^{18}$ \\ Apart from education, you also need good health. To have \\ good health, you must be active and maintain a healthy \\ diet. $^{15}$ \\ Because we are already sweet, so we don't have to eat too \\ much sweet anymore. *
}

By exercising your brain will become more concentrated, so that your productivity will be better. ${ }^{17}$

By exercising, the body becomes fit, healthy, and vibrant. *

Come on, let the spirit of your footstep, the farther you step the closer you are to health. ${ }^{15}$

Cooking oil already has a bad talent to the heart, and the crime increases when used repeatedly, just use a little and only once.*

Crying fat is happiness, let's be diligent in burning fat. ${ }^{15}$ Cut back on the snacks, it's too heavy ... the calories ... it's enough for me to be heavy already. *

Do you know that programmed and regular physical activity can make a person more concentrated?. ${ }^{17}$

Do you know that regular physical activity and a good diet can make a person happier mentally. ${ }^{17}$

Do you know that walking strengthens joints, muscles, and immunity, let's start now to get used to walking. ${ }^{17}$

Don't be sad, do exercise today, your endorphin makes you happy.*

The best achievement of a person is when he overcome laziness, let's move together for better health.*

Don't like vegetables? Switch to fruit or nuts. *

Drugs and Vitamins are not a guarantee of a healthy life. Maintain your heart, get rest, eat a balanced diet, and exercise regularly, these are the keys to a healthy life. ${ }^{15}$ Let's move on to the body, use music to make it more fun.

Exercise is for making the body healthy, not punishing what we have eaten because food is innocent. ${ }^{15}$

Exercise is King and the proper diet is queen. Combine both correctly and you will get a kingdom. ${ }^{15}$

Exercise is not a burden, but a lifestyle. ${ }^{15}$

Have you had any activities today? Where have you been? Let's move, get excited. ${ }^{17}$

Health always seems valuable after we lose. Let's start from now on, take care of your health by increasing your physical activity and maintaining a diet. ${ }^{19}$

Health depends on what we do and what we eat now, let's start from now on, improve our lifestyle.*

The one way to maintain health is to eat food according to your needs and increase your physical activity. ${ }^{15}$

Health is the most beautiful gift that we sometimes forget to be grateful. 15

*Own word
It's much harder to get people healthy than it is to make them sick. So keep healthy with exercise. ${ }^{15}$

Health is the most beautiful gift that we sometimes forget to be grateful for. Let's move. ${ }^{15}$

Healthy exercise doesn't have to be torturous, but routine and relaxing. ${ }^{*}$

Healthy is not punishing what we eat, because food is innocent. Let's pay it with exercise.

Let's clean up the house so that your mom will more love you. *

How are you today? How many steps have we taken today? I believe that if you are healthy, you can do anything. *

If there're 1000 reasons you do not care about your health, then they're always 1001 reasons to take care of it. $^{15}$

Keep stepping in the house, in the yard, nothing is limited even though all day at home.*

Let us make it a habit to walk, walk well for the heart. ${ }^{15}$

Let's get motivated to move our body until we dry for at least 15 minutes, 30 minutes is better. ${ }^{17}$

Let's get routine activity. Activities are useful for controlling weight, controlling blood pressure, and preventing diabetes. ${ }^{17}$

Let's love the heart, every beat is very precious. ${ }^{17}$

Exercise can build discipline, self-confidence, and good habits. ${ }^{20}$

The harder it is for you to start, the greater the joy you will get when you succeed in achieving it, let's active. ${ }^{15}$ Set the target as high as possible and don't stop until you meet it, how many steps have you taken today?. ${ }^{15}$ Sports, once we feel the benefits, then we will be addicted. ${ }^{15}$

Don't forget to eat breakfast, you can also eat vegetables.

The earlier you change your lifestyle to be healthier, the earlier you will see it. ${ }^{21}$

Let's move together for a healthy life. *

Health is a saving from daily behavior that has been carried out for a long time before your health is disturbed; let's take care of it. ${ }^{15}$

Tired now is the future happiness, let's get more steps.

Those who feel they do not have time to exercise; soon have to make time to treat their illness. ${ }^{15}$ The worst thing about exercise is when it never happens. ${ }^{15}$

There is good fat and bad fat, let's be friends with the good one, like plant fat. ${ }^{17}$

The reason I exercise is to enjoy my life longer*

The worst thing about exercise is when it never happens. 15

Two pleasures make people lose because they neglect it, healthy favors and free time, let's maintain the health that has been given. ${ }^{15}$

To enjoy the light of good health, you must be diligent in exercising and maintaining a healthy diet. ${ }^{15}$

True strength comes from within. The spirit of being number one, no one can make it happen except you. ${ }^{15}$

True treasure is health, not gold and silver. Come on, how many steps have you taken today?. ${ }^{22}$ 


\section{Physical Activity Assessment}

The level of physical activity was assessed using the International Physical Activity Questionnaire Short-Form version (IPAQ-SF). This questionnaire is simple and widely used. It has been recommended as a cost-effective method to assess physical activity. ${ }^{24}$ This questionnaire consists of 7 questions about physical activity. Respondents filled in on their physical activities during the last 7 days. The results were processed according to the IPAQ scoring protocol guidelines. Each physical activity was converted to units of metabolic equivalents of task (MET). For example, walking $2.7 \mathrm{~km} \mathrm{/} \mathrm{h}$ (relaxing) is 2.9 METs, watching television is $1 \mathrm{MET}$, jumping rope is 10 METs, and sleeping is 0.9 MET. MET values were multiplied by duration in minutes and accumulated as the final score of daily physical activity. ${ }^{25}$ Physical activity level was recorded 2 times. The first record was the average daily physical activity for the first 7 days after education. The second record was the average daily physical activity for the last 7 days at the end of the intervention.

\section{Assessment of Food Intake}

The Semi Quantitative-Food Frequency Questionnaire (SQ-FFQ) was used to assess calorie intake. The use of the SQ-FFQ was based on practicality. This questionnaire is recommended by the Ministry of Health of the Republic of Indonesia. ${ }^{26}$ The SQ-FFQ is a simple and flexible questionnaire that records food intake within a certain time. This questionnaire can detect the frequency of consumption and part of the food. Questions are directed because all the food ingredients that are filled in have been recorded on the form along with the part of the meal. Respondents find it easier to estimate the volume of food they consume. It does not need complicated preparation. ${ }^{27}$ Food intake can be filled according to the needs. The subject does not need to record in detail all the food and drink it consumes every day. This study tracked the subjects' food intake for 1 week. The 7-day range was chosen because the subjects still easily remember the food intake consumed. The history of calorie intake was taken twice daily for 7 days at the start of the program, and the last 7 days before the end of the program. ${ }^{26}$

\section{Blood Sample}

Blood samples were taken at 08.00-10.00 am. Subjects were requested to fast overnight before the examination. Blood samples were taken from cubital veins. A total of $3 \mathrm{~mL}$ of blood was taken for whole assessments. Around $2 \mathrm{~mL}$ was put into a tube without EDTA for the examination of serum lipids and $0.5 \mathrm{ml}$ of blood was put into a tube with EDTA for HbA1c measurements. About $0.5 \mathrm{ml}$ of the remaining blood was used for rapid immunoserological testing for COVID-19.

\section{Blood Lipid Profiles and HbA1c}

Total cholesterol, triglycerides, and HDL-C were mixed with Human ${ }^{\circ}$ working reagents. The level of those lipid profiles was measured by Dialab $\AA$ DTN-410-K spectrophotometer. LDL levels were calculated with Friedewald's formula. ${ }^{28}$ For HbA1C measurement, the whole blood was mixed with R1 NycoCard $\otimes$ reagent. The result was read on the NycoCardTM Reader II.

\section{Body Mass Index}

Body Mass Index (BMI) was calculated using the formula weight (kilograms) divided by height squared (meters) ${ }^{14}$ The subjects were advised to avoid coffee, tea, and exercise before the examination. Subjects were asked to dress in loose-fitting clothes. During measurements, subjects were asked to relax and breathe like usual. Height was measured with a digital stadiometer InBody Co., Ltd BSM-170®. The instrument was calibrated before the measurement session. Subjects in bare feet stood straight and stepped on the footplate with both feet in line, knees and legs straight, and heels touch the end of the footplate. The upper part of the measurement unit touched the head and the result can be shown on the screen. Bodyweight was measured using electronic body scale (Omron HBF-375 Karada Scan $®)$. The scanner was tuned automatically before each scanning. At the beginning of each measurement, data on date of birth, gender, and height were entered. Subjects place their bare feet on the foot electrodes, with knees and back straight. The examiner read and recorded the results of BMI that appeared on the screen.

\section{Data Analysis}

Data analysis using SPSS software version 16.0 (SPSS, Inc., Chicago, IL, USA). Continuous variables were expressed as mean \pm standard deviation (SD). An ANCOVA test was used to analyze data. The numeric after intervention data as dependent variable and the group as independent variable. Meanwhile, numeric before intervention data as covariate. All the numeric data exhibited normality and homogeneity in the variance with $p>0.05$.

\section{RESULTS}

After the subjects were educated, they were asked to join the social media group and their footsteps were monitored every day. Fig. 1 shows the average number of daily steps for the first 7 days, and the average daily steps for the 3 months of follow-up. In the first week, the two groups had no different daily steps. After monitoring for 3 months, the group that was given daily motivation had more daily steps than the control group. The pattern of physical activity for the first 7 days and the last 7 days of the program can be seen in Fig. 2 In the first 7 days, the group that was given daily motivation had a slightly better level of physical activity than the control group. In the last 7 days, 
the activity level of the group that was given daily motivation had a much better level of physical activity than the control group. The control group saw a decrease in daily steps and physical activity levels (fig. 1-2).

Figure 3 shows the amount of daily calorie intake. Both groups had similar daily calorie intakes at the early stages of the program. At the end of the program, the number of calorie intake for the group given daily motivation decreased lower than the control group. This shows that daily motivation gives a meaningful effect in improving the consumption volume. Figures 4,5 and 6 show the changes in HbA1C levels and lipid profiles. At the end of the program, the group that was given daily motivation had better $\mathrm{BMI}, \mathrm{HbA} 1 \mathrm{c}$, and all lipid profiles than control. Daily motivation affects improving the level of physical activity and calorie intake. The improvement of lifestyle may have a significant impact on those indicators.

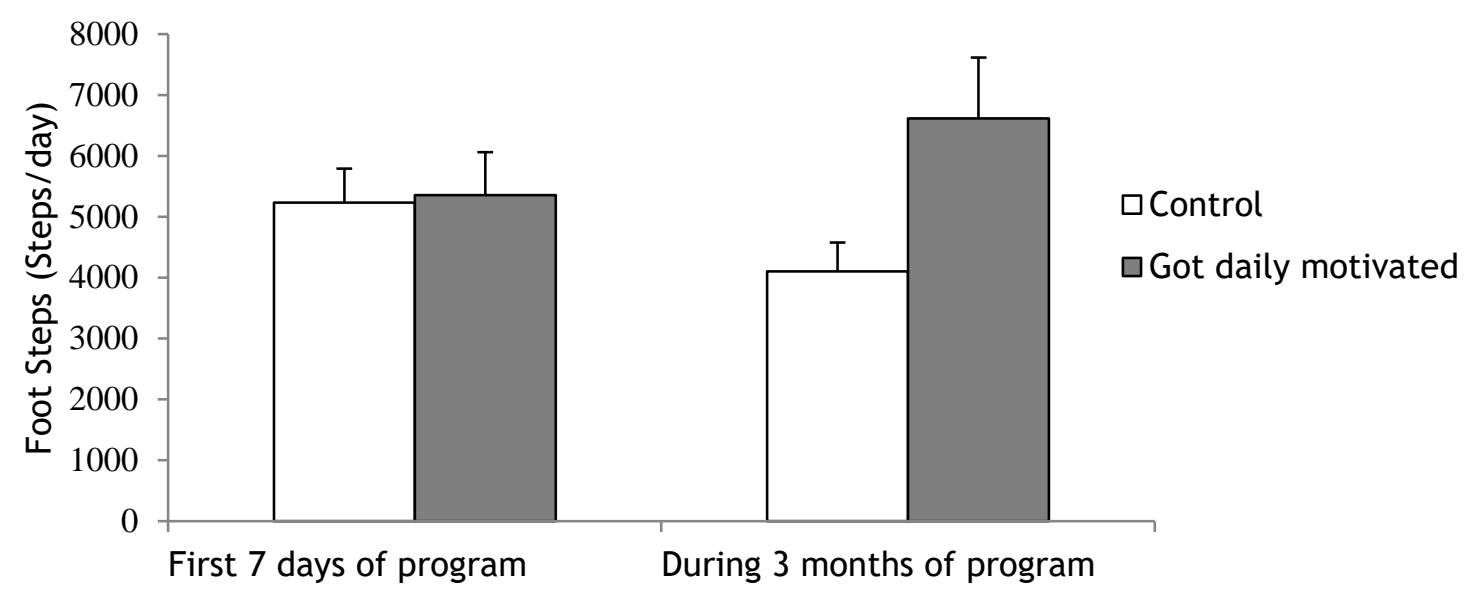

Fig. 1. The daily steps of the motivated group and the control group. An ANCOVA test on the 3 months daily step after controlling for the first 7 days of the program, gave a significant result $[F(1,157)$ =9.909; $p=0.022$ ]. $P$ value between group in first 7 days $(p=0.442)$; first 7 days vs 3 months of control group ( $p=0.082)$; first 7 days vs 3 months of intervention group $(p=0.034)$. This shows that motivation has a better effect on the average daily steps of the intervention group than the control group.

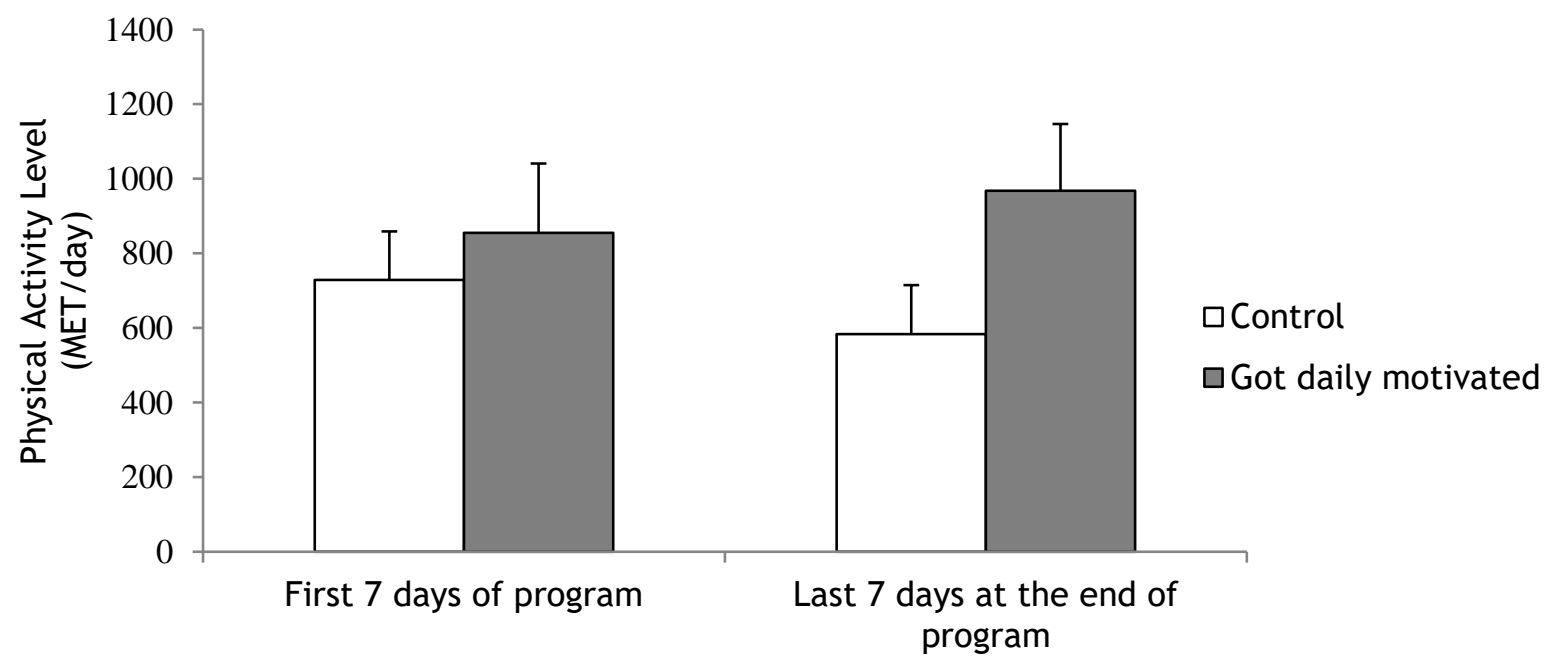

Fig.2. Levels of physical activity in the daily motivated and control group. ANCOVA test results after controlling for the first 7 days of the program, showed a significant result $[F(1,157)=40.470 ; p<0.001]$. $P$ value between group in first 7 days $(p=0.236)$; first 7 days vs 3 months of control group $(p=0.042)$; first 7 days vs 3 months of intervention group $(p=0.013)$. This shows that daily motivation has a better effect on physical activity than the control group. 


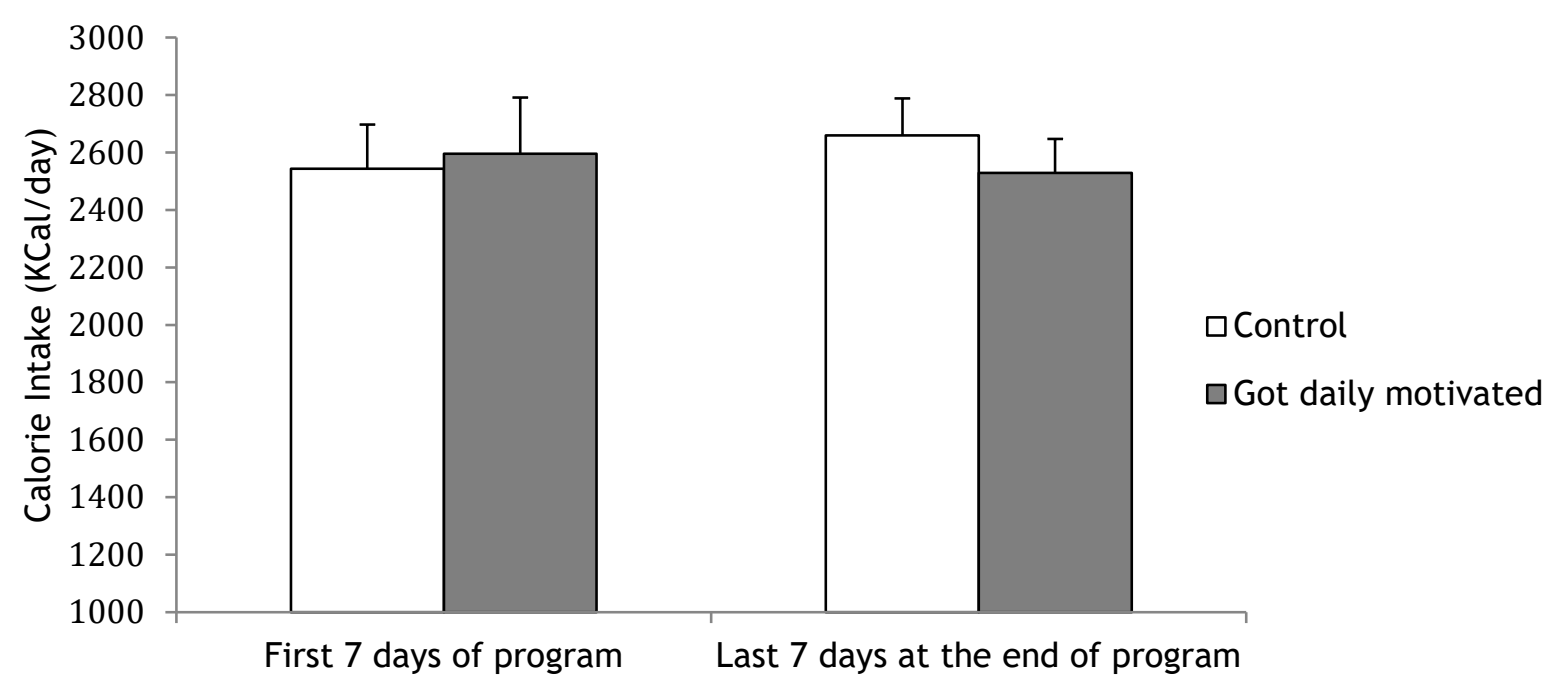

Fig. 3. The number of calorie intakes of the group given daily motivation and the control group. ANCOVA test results after controlling for the first 7 days of the program, showed a significant value $[F(1,157)=$ 6.692; $p=0.04$ ]. $P$ value between group in first 7 days $(p=0.681)$; first 7 days vs 3 months of control group $(p=0.304)$; first 7 days vs 3 months of intervention group $(p=0.046)$. Daily motivation affects decreasing the calorie intake for the last 7 days of the program.

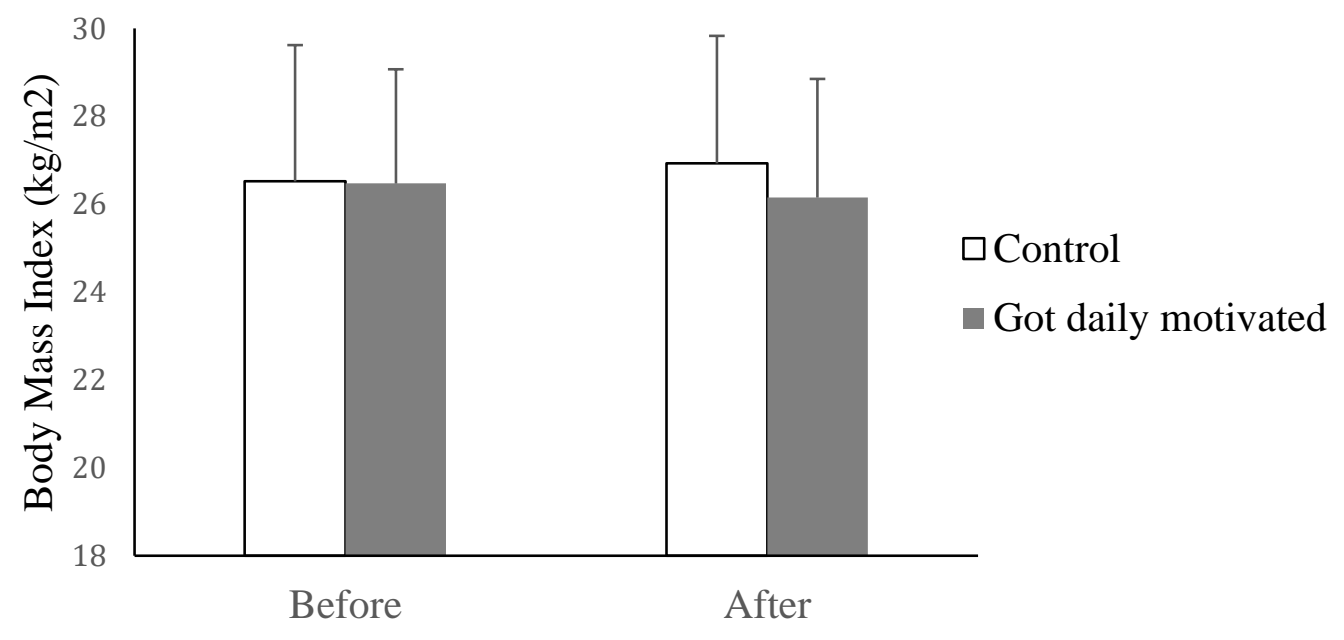

Fig.4. Body Mass Index (BMI) of daily motivated and control group. An ANCOVA test result after controlling for $B M I$ before intervention showed a significant value $[F(1,157)=5.958, p=0.042]$. $P$ value between group in before intervention $(p=0.325)$; before vs after intervention of control group $(p=0.012)$; before vs after intervention of group $(p=0.036)$. Daily motivation affects decreasing the BMI, while the $\mathrm{BMI}$ increased in the control group. 


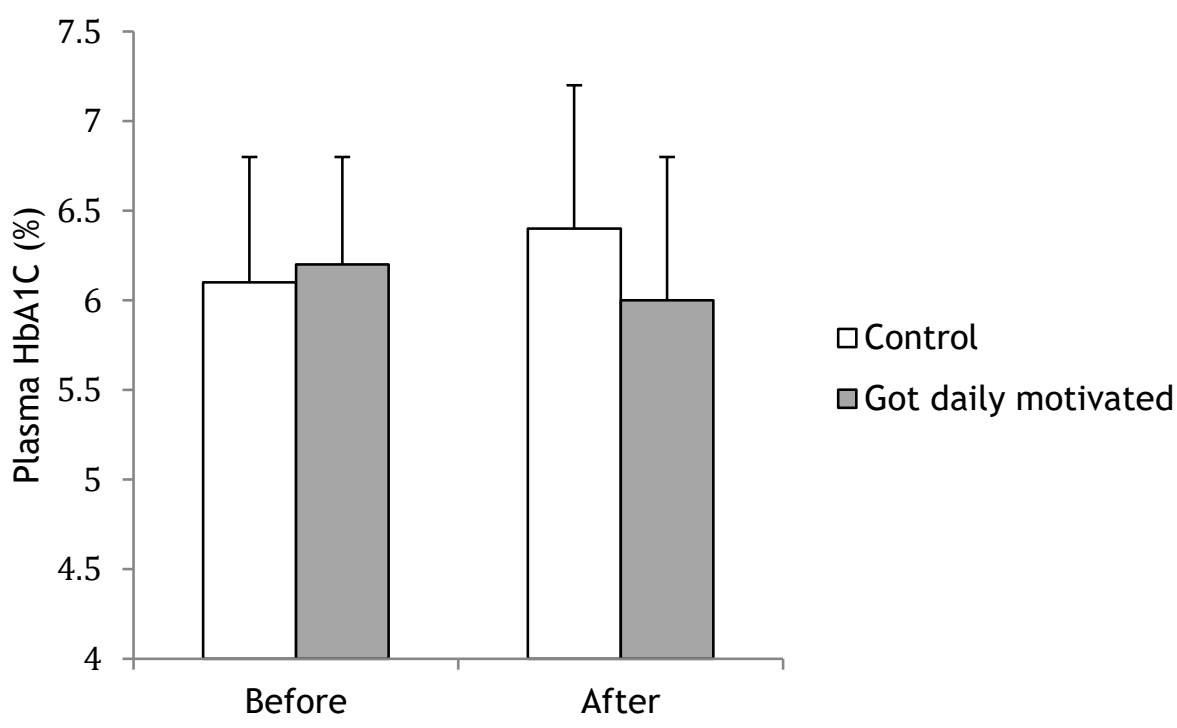

Fig.5. HbA1c levels in the daily motivated group and control group. An ANCOVA test result after controlling for HbA1C levels before intervention showed a significant result $[F(1,157)=39.069$, $p=0.008]$. $P$ value between group in before intervention $(p=0.161)$; before vs after intervention of control group $(p=0.004)$; before vs after intervention of intervention group $(p=0.016)$. This indicates that motivation has an impact on the improvement of HbA1C levels.

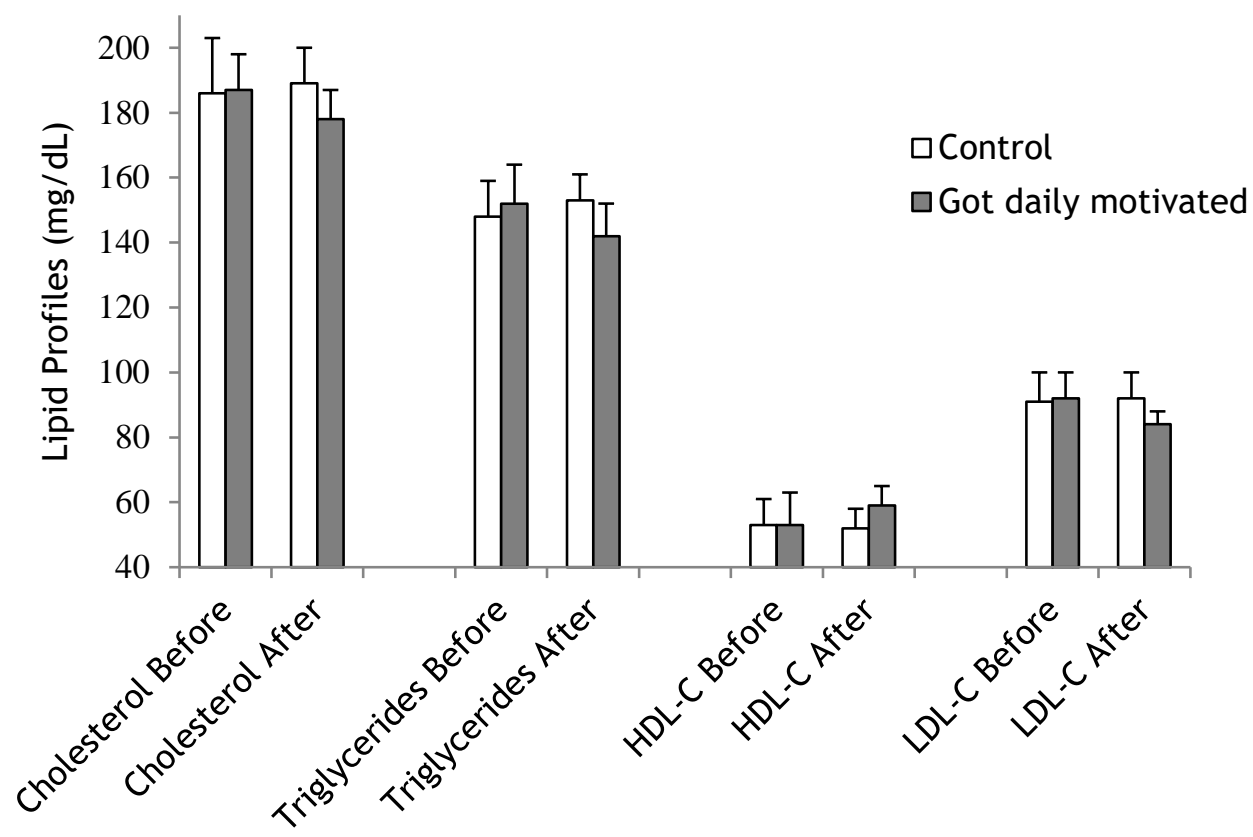

Fig.6. Lipid profiles in the daily motivated and control groups. ANCOVA test has been performed by controlling the lipid profile before intervention. Motivation has a significant effect on improving total cholesterol $[F(1,157)=6.364, p<0.05]$, triglycerides $[F(1,157)=7.027 ; p=0.035], \operatorname{HDL}-C[F(1,157)$ $=7.811, p=0.032]$, and LDL-C $[F(1,157)=8.143, p=0.028]$. $P$ value between group in before intervention: cholesterol $(p=0.561)$; triglycerides $(p=0.188)$; HDL-C $(p=0.734)$; LDL-C $(p=0.582)$. P value before vs after intervention of control group: cholesterol $(p=0.222)$; triglycerides $(p=0.039)$; HDL-C $(p=0.731)$; LDL-C $(p=0.154)$. $P$ value before vs after intervention of intervention group: cholesterol $(p=0.007)$; triglycerides $(p=0.011)$; HDL-C $(p=0.026)$; LDL-C $(p=0.036)$.

\section{DISCUSSION}

This study reveals continuous daily motivation improves the lifestyle of the students. Research on motivation through social media for lifestyle improvement has been reported. The motivation conveyed through social media was effective to improve physical activities. ${ }^{29}$ Motivation can be given in two types, in the form of support and competition. The competition turned out to be more effective than supportive to increase physical activity. ${ }^{30}$ Our study seeks to combine these two types of motivation. Supportive motivation has been given to intervention groups, in the form of short messages. Competition motivation has been given to both groups in the form of step recordings that can be known by all members of each group. The group given a 
combination of motivation had a better effect than the controls that only got the competition motivation. Supportive motivational sentences have benefits in improving lifestyle. ${ }^{31}$

Another motivation that is considered effective is reward and punishment. ${ }^{32}$ This study was not feasible to give rewards and punishment to students. Reward and punishment only effective if the subject has a high dependence on a program. This study only rewards in the form of praise sentences, for those who have good achievements. Reward and punishment systems are also considered to be cost-ineffective, and situational. ${ }^{33}$

In this study, all groups received explanations and motivation at the beginning of the program. Then, the intervention group received daily motivation with a supportive short message. Supportive motivation seems to be effective enough for higher achievement as long as it is given regularly. Previous studies have also proven that continuous motivation was effective in improving lifestyle. Providing supportive messages 2 times a week for 3 months significantly increased the level of moderate activity. ${ }^{31}$ Short messages also affected the increasing number of daily steps and VO2max. ${ }^{34}$ The urge to increase motivation is attention. Daily messages, although in the form of short sentences will stimulate attention. ${ }^{35}$ Repeated messages also give long-term potentiating (LTP) effect and memory strengthening. Those are resulting in habituation. Habituation causes individuals to become familiar with the stimulus. ${ }^{36,37}$ Attention and familiarity cause individuals to feel comfortable and start liking the message. Thus, they are moved to behave according to the message. ${ }^{35,36}$ However, the short message provided must vary. The same message given regularly has no impact on increased motivation. ${ }^{35}$

During the pandemic, effective media is needed to replace face-to-face interaction. This study proved that the use of smartphones was effective for remote physical education teaching. Step counters (pedometer) in smartphones can help to carry out regular monitoring of a student's physical activity. A meta-analysis study showed that step counters increased the physical activity of diabetic patients. ${ }^{38}$ Pedometer applications on smartphones have also been compared to conventional pedometers. The increase in the number of steps in Smartphone app users was greater than that of traditional pedometer users. This is because the use of Smartphone apps has competitive features by comparing the footsteps of other members. ${ }^{39}$

In this study, improvements in physical activity had an impact on improving BMI, lipid, and sugar profiles. Physical activity is associated with the improvement of lipid profiles. Physical exercise for 8 weeks in obese children was able to improve the levels of total cholesterol, triglyceride, LDL, VLDL, and HDL. ${ }^{40}$ The exercise was also efficient in reducing total cholesterol and LDL levels of children and adolescents. ${ }^{41}$ Physical activity increases the enzyme lipoprotein lipase (LPL) which triggers triglyceride hydrolysis. It also suppresses the enzyme protein activator proprotein convertase subtilisin/Kexin type 9 (PCSK9). The decrease in PCSK9 makes more LDL absorbed and excreted by the liver to the gut. The transcription factor of the Liver $X$ receptor (LXR) will also increase. This factor triggers the transfer of cholesterol from adipose to the liver in HDL form. ${ }^{42,43}$ Physical activity has also been shown to improve HbA1c levels. A meta-analysis study also showed that exercise was associated with improvement $\mathrm{HbA1C} .{ }^{44}$ The increase in physical activity was associated with reductions in both fasting glucose and HbA1C. ${ }^{45}$ The American College of Sports Medicine (ACSM) recommends accumulating 150 minutes of moderate-intensity or 60 minutes of vigorous-intensity aerobic exercise per week to control blood glucose in type II diabetics. ${ }^{46}$ Skeletal muscle is responsible for taking up $70-90 \%$ of the glucose from the blood. Muscle contraction triggers insulin activation to be delivered to the muscle. Insulin triggers an increase in GLUT-4, the most abundant glucose transporter in the muscle (GLUT-4). Insulin and muscle contraction stimulate the translocation of GLUT 4 from intracellular to cell surface, to take up glucose into the cell. ${ }^{47}$ Recurrent muscle contractions will also activate the enzyme glycogen-synthase. This enzyme will increase glucose disposal. ${ }^{48}$

Improvements in BMI, sugar, and lipid profiles in this study may also be affected by decreased calorie intake. Moderate CR in combination with physical activity has beneficial effects even in the non-obese group. $\mathrm{CR}$ was achieved through intermittent fasting or restricting feeding. ${ }^{49}$ Calorie restriction enhanced peripheral insulin sensitivity. ${ }^{50}$ Lowering calorie intake also improves the body weight, lipid profile in healthy, obese, and dyslipidemia persons. ${ }^{51}$

The weakness of this study was the used of IPAQSF to assess physical activity. A systematic review has shown that IPAQ-SF as an indicator of physical activity was weak. However, its reliability showed it could be used in repeated measures studies. ${ }^{24}$ Another systematic review has proven that IPAQSF has repeatability at an acceptable level. ${ }^{52}$ This study was not intended to look for absolute levels of physical activity. This study was only to compare changes in physical activity patterns.

This study only provided interventions in the form of short motivation and self-monitoring. Future interventions should be developed in the form of structured physical exercise programs. The subjects will be provided by measurable frequency, intensity, volume, and type of exercise. Exercise programs that are guided and 
monitored through Smartphones have been widely developed. The study of the impact of this longdistance program on health will be very interesting.

\section{CONCLUSION}

During the pandemic, daily motivation through social media was effective to improve the lifestyle. It has a positive impact on improving the profile of BMI, lipids, and sugar in overweight and obese teens. Programs to maintain a healthy lifestyle in children must be implemented continuously. Therefore, a synergistic collaboration between teachers and parents/guardians is needed.

\section{Conflict of interest}

The authors declare no potential conflict of interest.

\section{Acknowledgements}

The authors wish to thank the students of "Number 1" State High School who participated in this study. Thank you to the school teachers, and health officers of the Palembang City Health Office who helped the implementation of this study. Finally, we also thank the team from the Department of Physiology, Faculty of Medicine Sriwijaya University who showed their great dedication and professionalism.

\section{REFERENCES}

1. Allam, Z. 2020. The First 50 days of COVID-19: A Detailed Chronological Timeline and Extensive Review of Literature Documenting the Pandemic, In: Surveying the Covid-19 Pandemic and its Implications. Elsevier. https: / / www.ncbi.nlm.nih.gov/pmc/articles/PM C7378494/pdf/main.pdf (accessed 2020 October 21).

2. Ghosal, S., Bhattacharyya, R., and Majumder, M. 2020. Impact of complete lockdown on total infection and death rates: A hierarchical cluster analysis. Diabetes Metab Syndr Clin Res Rev 14:707-711.

3. Suraya, I., Nurmansyah, M.I., Rachmawati, E., et al. 2020. The Impact of Large-scale Social Restrictions on the Incidence of COVID-19 : A Case Study of Four Provinces in Indonesia. Jurnal Kesehatan Masyarakat Nasional (National Public Health Journal) Special Issue 1: 4953.

4. Zheng, C., Yajun, H.W., Sheridan, S., et al. 2020. COVID-19 pandemic brings a sedentary lifestyle: a cross-sectional and longitudinal study. https: / / www.medrxiv.org/content/10.11 01/2020.05.22.20110825v1 (accessed
2020 June 16).

5. Xiang, M., Zhang, Z., and Kuwahara, K. 2020. Impact of COVID-19 pandemic on children and adolescents' lifestyle behavior larger than expected. Prog. Cardiovasc. Dis 63:531-532.

6. Heinonen, I., Helajärvi, H., Pahkala, K., et al. 2013. Sedentary behaviours and obesity in adults: The cardiovascular risk in young finns study. BMJ Open. 3:e002901.

7. Cook, S., Ellen, R., and Kavey, W. 2011. Dyslipidemia and Pediatric Obesity. Pediatr Clin North Am.58:1363-1373.

8. Magge, S.N, Goodman, E., and Armstrong, S.C. 2017. The metabolic syndrome in children and adolescents: shifting the focus to cardiometabolic risk factor clustering clinical report guidance for the clinician in rendering pediatric care. www.aappublications.org/news Accessed 2020 May 21).

9. Turer, C.B., Brady, T.M., and De Ferranti, S.D. 2018. Obesity, hypertension, and dyslipidemia in childhood are key modifiable antecedents of adult cardiovascular disease. Circulation 137:1256-1259.

10. Herouvi, D., Karanasios, E., Karayianni, C., et al. 2013. Cardiovascular disease in childhood: The role of obesity. Eur. J. Pediatr 172:721-232.

11. Guo, H., Zeng, X., Zhuang, Q., et al. 2015. Intervention of childhood and adolescents obesity in Shantou city. Obes Res Clin Pract 9:357-364.

12. Stark, J. 2017. Why physical education should be mandatory in schools $(\mathrm{k}-12)$. https: / /digitalcommons. murraystate.edu /bis437/55 (accessed 2020 May 23).

13. World Health Organization. 2020. Clinical management of covid-19. file: / / C: /Users/CBT/Downloads/WHO2019-nCoV-clinical-2020.5-eng.pdf (accessed 2020 June 21).

14. World Health Organization. 2020. Obesity and overweight. https: / /www. who.int/news-room/factsheets/detail/obesity-and-overweight (accessed 2020 May 28).

15. Najmah, D.J. 2008. 40 Kata-kata motivasi rajin berolahraga, bikin semangat hidup sehat (40 Motivational words to exercise, make the spirit of healthy life). 
https: / /www.brilio.net/wow/40-katakata-motivasi-rajin-berolahraga-bikinsemangat-hidup-sehat-200826e.html (accessed 2020 August 28).

16. Gojanovic, B. 2019. We do not stop exercising because we grow old - we grow old because we stop exercising; $\mathrm{Dr}$ Kenneth Cooper. https://semsjournal.ch/6879?pdf=6879 (accessed 2020 July 20)

17. Kementerian Kesehatan Republik Indonesia. 2018. Manfaat aktivitas fisik (Benefits of physical activity). http: / / www.p2ptm.kemkes.go.id/infogr aphic-p2ptm/hipertensi-penyakitjantung-dan-pembuluh-darah/manfaataktivitas-fisik (accessed 2020 July 20).

18. Yayasan Lembaga Konsumen Indonesia. 2014. Sehat ada di tangan kita (Healthy is in our hands). http: / /ylki.or.id/2014/09/sehat-ada-ditangan-kita/(accessed 2020 May 28).

19. Wellness for the win. 2017. Our health always seems much more valuable after we lose it. https: / / wellnessforthewin.com/ourhealth-always-seems-much-morevaluable-after-we-lose-it/ (accessed 2020 May 28).

20. Lifestyle Wolipop. 2012. Sembilan alasan olahraga bisa meningkatkan rasa percaya diri (Nine reasons exercise can boost confidence).

https: / / wolipop.detik.com/health-anddiet/d-2077135/9-alasan-olahraga-bisameningkatkan-rasa-percaya-diri (accessed 2020 May 28).

21. Pertamakali.com. 2020. Motivasi dan kutipan kata tentang berpikir positif (Motivation and word quotes about positive

https: / pertamakali.com/kata-kata thinking). berpikir-positif/ (accessed 2020 May 28).

22. Kompasiana Beyond Blogging. 2020. Bukan emas dan perak, harta sejati adalah Kesehatan (Not gold and silver, true treasure is health). https: / /www.kompasiana.com/pranatari ano/ 5f578966097f3603837088b3/bukanemas-dan-perak-harta-sejati-adalahkesehatan (accessed 2020 May 28).

23. Walk Across Texas. Org. 2019. Pedometer/step counter apps- our top picks.

https: / / walkacrosstexas.org/images/reso urces/Pedometer_Step_Counter_AppsFeb _2019.pdf (accessed 2020 May 12].
24. Lee, P.H, Macfarlane, D.J, Lam, T.H., et al. 2011. Validity of the international physical activity questionnaire short form (IPAQ-SF): A systematic review. Int. J. Behav. Nutr Phys Act 8:1-11.

25. The IPAQ Group. 2015. Guidelines for data processing and analysis of the international physical activity questionnaire. http://www.ipaq.ki.se (accessed 2020 April 12).

26. Sirajuddin., Surmita., and Astuti, T. 2018. Bahan Ajar Gizi, Survey Konsumsi Pangan (Nutrition Teaching Materials, Food Consumption Survey). Jakarta: Kementrian Kesehatan Republik Indonesia: Pusat Pendidikan Sumber Daya Manusia Kesehatan (Ministry of Health of the Republic of Indonesia: Center for Education and Human Resources for Health).

27. Cheng, G., Hilbig, A., Drossard, C., et al. 2013. Relative validity of a $3 \mathrm{~d}$ estimated food record in German toddlers. Public Health Nutr 16: 645-652.

28. Pradhan, S., Gautam, K., and Pyakurel, D. 2020. Comparison of calculated LDLcholesterol using the Friedewald formula and de Cordova formula with a directly measured LDL-cholesterol in Nepalese population. Pract Lab Med 20:e00165.

29. Al-Eisa, E., Al-Rushud, A., Alghadir, A., et al. 2016. Effect of motivation by "instagram" on adherence to physical activity among female college students. Biomed Res Int 2016:1-6.

30. Zhang, J., Brackbill, D., Ma, Y., et al. 2016. Support or competition? How online social networks increase physical activity: A randomized controlled trial. Prev Med Rev2016;4:453-458.

31. Kinnafick, F.E., Thøgersen-Ntoumani, C., and Duda, J. 2016. The effect of need supportive text messages on motivation and physical activity behaviour. 2016. J Behav Med2016;39:574-586.

32. Putra, M., and Damayanti, N.E. 2020. The Effect of Reward and Punishment to Performance of Driver Grabcar in Depok. International Journal of Research and Review 7:312-319.

33. Gerard, J. 2020. Disadvantages of Rewarding Employees With Gifts. https: / /smallbusiness.chron.com/disadva ntages-rewarding-employees-gifts24166. html (accessed 2020 October 29). 
34. Santoso, B., Irfannuddin, I., Swanny, S., et al. 2019. The effect of physical activity motivation to daily step count and VO2max. J PhysConf Ser 1246:012054.

35. Suri, G., and Gross, J.J. 2015. The role of attention in motivated behavior. J. Exp. Psychol. Gen 144:864-872.

36. Daalmas, J. 2012. Human Behavior in Hazardous Situations, Best Practice Safety Management in the Chemical and Process Industries. Ed.1. Butterworth-Heinemann

37. Paradiso, M.A, Bear, M.F, and Connors, B.W. 2007. Neuroscience: Exploring the Brain. Hagerstown: Lippincott Williams \& Wilkins

38. Qiu, S., Cai, X., Chen, X., et al. 2014. Step counter use in type 2 diabetes: A metaanalysis of randomized controlled trials. BMC Med 12:1-9.

39. Walsh, J.C., Corbett, T., Hogan, M., et al. 2016. An mhealth intervention using a Smartphone app to increase walking behavior in young adults: A pilot study. JMIR mHealthuHealth 4: e109 1-9.

40. Mahgoub, M.S.E., and Aly, S. 2015. The effects of continuous vs intermittent exercise on lipid profile in obese children. Int J TherRehabil 22:272-276.

41. Costa, R.R., Barroso, B., Reichert, T., et al. 2020. Effects of supervised exercise training on lipid profile of children and adolescents: Systematic review, metaanalysis and meta-regression. Sci Sports 36:321-329.

42. Wang, Y., and Xu, D. 2017. Effects of aerobic exercise on lipids and lipoproteins. Lipids Health Dis 16:1-8.

43. Zhang, L., Song, K., Zhu, M., et al. 2016. Proprotein convertase subtilisin/kexin type 9 (PCSK9) in lipid metabolism, atherosclerosis and ischemic stroke. Int. J. Neurosci 126:675-680.

44. Jang, J.E, Cho, Y., Lee, B.W., et al. 2019. Effectiveness of exercise intervention in reducing body weight and glycosylated hemoglobin levels in patients with type 2 diabetes mellitus in Korea: A systematic review and meta-nalysis. Diabetes Metab J 43: 302-318.

45. Boniol, M., Dragomir, M., Autier, P., et al. 2017. Physical activity and change in fasting glucose and HbA1c: a quantitative meta-analysis of randomized trials. Acta Diabetol 54:983-991.

46. American College of Sport Medicine. 2018. Postprandial exercise and glucose regulation for type II diabetics: Considerations for ACSM guidelines. https: / / www.acsm.org/all-blogposts/certification-blog/acsm-certifiedblog/2018/06/29/ postprandial-exerciseand-glucose-regulation-for-type-iidiabetics-considerations-for-acsmguidelines (accessed 2020 October 16).

47. Evans, P.L, McMillin, S.L, Weyrauch, L.A., et al. 2019. Review: Regulation of skeletal muscle glucose transport and glucose metabolism by exercise training. Nutrients 11:2-24

48. Manabe, Y., Gollisch, K.S.C., Holton, L., et al. 2013. Exercise training-induced adaptations associated with increases in skeletal muscle glycogen content. FEBS $J$ 280:916-926.

49. Most, J., Tosti, V., Leanne, M., et al. 2017. Calorie restriction in humans: an update. Ageing Res Rev 39:36-45.

50. Johnson, M.L., Distelmaier, K., Lanza, I.R, et al. 2016. Mechanism by which caloric restriction improves insulin sensitivity in sedentary obese adults. Diabetes 65:74-84.

51. Santos, H.O., and Macedo, R.C.O. 2018. Impact of intermittent fasting on the lipid profile: Assessment associated with diet and weight loss. Clin. Nutr. ESPEN 2018;24:14-21.

52. Craig, C.L., Marshall, A.L, Sjostrom, M., et al. 2003. International physical activity questionnaire: 12-country reliability and validity. Med. Sci. Sports Exerc 35: 13811395. 